\title{
Comparison of Propofol with Butorphanol and Propofol with Fentanyl for Total Intravenous Anaesthesia in Short Surgical Procedures
}

\author{
Aakash Trivedi ${ }^{1}$, Dhavalkumar C Patel ${ }^{2}$ \\ ${ }^{1}$ Senior Resident, GMC Surat, Gujarat, ${ }^{2}$ Assistant Professor, GMC Surat, Gujarat.
}

\section{Abstract}

Background: Total intravenous anaesthesia is a technique in which induction and maintenance of anaesthesia is achieved with intravenous drug alone. With analgesics complete anaesthesia can be achieved. Objectives: To study \& compare the hemodynamic profile, intra operative analgesic adequacy, VAS score and emergence time between two groups. Subjects and Methods: Total 80 patients of ASA grade I \& II, aged 18-60years old, who were posted for short surgical procedures were randomly divided into two groups. Group I received Inj.Butorphanol $20 \mu \mathrm{g} / \mathrm{kg}$ and Group II received Inj.Fentanyl $2 \mu \mathrm{g} / \mathrm{kg}$ body weight. Both the groups received Inj. Propofol $2 \mathrm{mg} / \mathrm{kg}$ I.V. and then maintenance of anaesthesia started with Propofol as a stepped down scheme. Intra operative depth of anaesthesia was monitored using clinical signs like rise in blood pressure, pulse and respiratory rate. Post-operative sedation score was noted using Ramsay Sedation score. Visual analogue score for pain, was noted at the time of emergence time. Results: Respiratory rate, heart rate and $\mathrm{SpO} 2$ showed no significant differences between groups. Average systolic and diastolic BP in group I was lower as compared to group II during the surgery and post-operative at the time of emergence also. Mean emergence time in group I was significantly higher than group II. Mean VAS at the time of emergence was significant less in butorphanol group. Conclusion: From the present study it can be concluded that, Butorphanol \& Fentanyl combined with Propofol are comparable in hemodynamic profile. Post-operative more time is taken for emergence in Butorphanol group. VAS score for pain at the time of emergence is more in Fentanyl group compared to Butorphanol. With conventional monitoring, depth of anaesthesia is satisfactory between groups. With both the drugs satisfactory anaesthesia can be provided for short surgical procedures which are 30 or less in duration.

Keywords: Total intravenous Anaesthesia (TIVA), Propofol, Fentanyl, Butorphanol, Ramsay Sedation score (RSS), Visual analogue score (VAS).

Corresponding Author: Dr. Dhavalkumar C patel, Assistant Professor, GMC Surat, Gujarat.

Received: November 2019

Accepted: November 2019

\section{Introduction}

TIVA is a general anaesthesia technique which contains sole intravenous agents to anaesthetize the patient without any inhalational agent. Real advance in intravenous anaesthesia took place during 1921 when Daniel and Gabriel Bardet published their experiences using somnifaine. ${ }^{[1]}$ Fredet and Perlis combined somnifaine with subcutaneous injection of morphine to supplement the effects of somnifaine. ${ }^{[1]}$ Vann's $10 \mathrm{ml}$ syringe was used for this injection and for continuous intravenous infusion Abel's syringe was used. ${ }^{[2]}$

Total intravenous anaesthesia (TIVA) is a technique in which induction and maintenance of anaesthesia is achieved with intravenous drug alone and overcomes some of the disadvantages of traditional inhalation anaesthesia. Because of Speedy \& complete recovery with decreased postoperative nausea \& vomiting, early ambulation as well as reduces the cost of hospital stay, TIVA is suitable for day care surgeries. It has least risk of malignant hyperthermia syndrome and environmental hazards like operation theatre pollution which may be seen with inhalational agents, ${ }^{[3,4]}$

With the invention of newer induction agents, analgesics and amnestic agents having shorter half-life and advents of infusion pumps/syringe pump chances of anaesthesia related complications have been decreased. That's why TIVA is now promoted day by day. ${ }^{[5]}$ The concept of intravenous anaesthesia (IV) has progressed over a period of time largely due to the better understanding of pharmacokinetics and pharmacodynamics along with the development of Intravenous (IV) drug delivery systems that are able to titrate and deliver accurately the infusion dose of a given Intravenous agent. Now a days objectively we can measure the depth of anaesthesia also.

The goals of outpatient ambulatory anaesthesia include a rapid and smooth induction, effective intraoperative anaesthesia and a smooth and fast recovery. ${ }^{[6,7]}$ Postoperative side effects are also minimal, so that an early discharge is possible. ${ }^{[8]}$ There are many drugs which can be used as an induction agent like Propofol, Thiopentone, Methohexitol, Etomidate etc. Of all the intravenous anaesthetic agents that are available, Propofol's pharmacokinetic profiles favour administration by continuous intravenous infusion. ${ }^{[9,10]}$

Propofol a GABA modulator is a newer intravenous anaesthetic agent, having favourable pharmacokinetic profile. It has a high clearance rate and rapid decline in blood 
concentration, making it choice of agent for infusion. Propofol has emerged as a gold-standard for TIVA for short surgical procedures and day care ambulatory surgery but its main shortcoming is lack of analgesia, therefore it has to be combined with an analgesic. ${ }^{[8-10]}$

As pump technology is expensive, there may still be an option for ketamine as a single all-purpose drug in settings of limited resources. ${ }^{[11]}$ Ketamine is traditionally associated with slower emergence and some incidence of unpleasant hallucinations even when given in moderate doses for sedation. $^{[11]}$

Pain relief forms an important part of balanced anaesthesia. There are various drugs that can be used as an analgesic; like Ketamine, Fentanyl, Sufentanil, Butorphanol etc. Butorphanol is an agonist-antagonist opioid that resemble pentazocine. The prime advantages of this agent is potent analgesia, low toxicity, longer duration of action and very low potential for abuse. ${ }^{[12,13]}$ Fentanyl is a synthetic opioid acting on the $\mu(\mathrm{mu})$ receptors and is almost 100 times more potent than morphine. ${ }^{[14]}$ Fentanyl has relatively short duration of action. Sufentanil like opioid has good analgesic quality but has very short duration of action.

Hence, we planned to compare Propofol with Butorphanol and Propofol with Fentanyl in short surgical procedures under Total Intravenous Anaesthesia technique.

\section{Aims and Objectives}

To study \& compare the hemodynamic profile and intra operative analgesic adequacy of intravenous Propofol with Butorphanol (Group I) and Propofol with Fentanyl (Group II) in Total Intravenous Anaesthesia. To compare \& evaluate the emergence time and VAS score post procedure between two group.

\section{Subjects and Methods}

Institutional Ethical Committee (IEC) approval was taken prior to study and Informed consent was obtained from all the 80 patients. Study was conducted between age group of 18 to 60 years of either sex having American Society of Anesthesiologist (ASA) Grade I \& II and posted for elective short duration (up to $30 \mathrm{~min}$ ) superficial surgery procedure in supine position. Surgeries requiring manipulation of deeper structure, emergency surgeries, patients requiring intubation, patients with contraindications to any of the study drug, patients with any neurological and psychological condition were excluded.

All patients were kept fasting overnight and tab. Pantoprazole $(40 \mathrm{mg})$ at 10 p.m. was advised to them. Preoperative explanation of the procedure and VAS was noted to gain confidence of the patients and written consent was taken for the same. ${ }^{[15]}$ On the day of surgery, in recovery room vitals are noted and I.V. access secured using $18 \mathrm{G}$ IV cannula and infusion of Ringer's Lactate @ 8ml $/ \mathrm{kg} / \mathrm{hr}$ started. All patients were premedicated with intravenous $0.004 \mathrm{mg} / \mathrm{kg}$ Glycopyrrolate. In operation theatre patients were kept supine on horizontal operating table and pre-operative vitals $\mathrm{BP}, \mathrm{SpO} 2 \mathrm{HR}$ and RR were noted (T0).

With the help of computer-generated random number table, patients were divided into 2 groups of 40 patients each. In
Group I Butorphanol $20 \mu \mathrm{g} / \mathrm{kg}$ body weight in $10 \mathrm{ml}$ syringe was given. In Group II Fentanyl $2 \mu \mathrm{g} / \mathrm{kg}$ body weight in $10 \mathrm{ml}$ syringe was given. In both groups after 5 minutes Propofol $2 \mathrm{mg} / \mathrm{kg}$ body weight given in concentration of $10 \mathrm{mg} / \mathrm{ml}$ and then maintenance of anaesthesia was started with Propofol as a stepped down scheme. Propofol $125 \mathrm{mcg} / \mathrm{kg} / \mathrm{min}$ for the first 10 minutes then $100 \mathrm{mcg} / \mathrm{kg} / \mathrm{min}$ for the next 10 minutes followed by $75 \mathrm{mcg} / \mathrm{kg} / \mathrm{min}$ till the end of surgery was given. 1 minute after analgesics vitals were noted (T1). After 5 minutes of the analgesics (T2) dose Inj. Propofol $2 \mathrm{mg} / \mathrm{kg}$ was given I.V. slowly over 1 minute. After 2 minutes vitals were again noted (T3). Then maintenance of anaesthesia was started with Propofol as a stepped down scheme as mentioned above. Vitals were noted at the time of skin incision (T4) and then every 5 minutes till the end of surgery (T5, T6, T7). Intra operative depth of anaesthesia was monitored using clinical signs like rise in blood pressure, pulse, limb movements, lacrimation and sweating. ${ }^{[16-18]}$ Propofol drip was stopped as soon as surgery ended and vitals were noted (T9). Duration of surgery was noted from the start of incision/procedure to the end of surgery. Postoperative sedation score was noted using Ramsay Sedation score (RSS) after stoppage of Propofol drip every 2 minutes till minimum sedation score came to 3 . Vitals were noted at the time of full awareness when minimum sedation score 3 . This emergence time was calculated from the stoppage of propofol drip to minimum sedation score 3(T10). Visual analogue score (VAS) for pain, was noted at the time of emergence time. All patients were on spontaneous breathing using oxygen with face mask at flow of $5 \mathrm{lit} / \mathrm{min}$. O 2 was started after giving analgesic drugs in both the groups. Intra operative and immediate post-operative complications like hypotension (BP $<20 \%$ baseline value), bradycardia (pulse $<20 \%$ baseline value), tachycardia (pulse $>20 \%$ baseline value) or others were looked for and treated accordingly.

\section{$\underline{\text { Statistics }}$}

Descriptive statistical analysis has been carried out. Result on continuous measurements are presented on mean \& SD and results on categorical measurements are presented in number i.e. No. (\%). Unpaired ' $\mathrm{t}$ ' test was used for comparisons of quantitative data between two independent groups. Chi-square test was used for qualitative data analysis. $\mathrm{S}=$ suggestive significant $(\mathrm{P}$ value $<0.05)$, NS = not significant $(\mathrm{P}$ value $>0.05)$. Open epi was used for the analysis of the data and Microsoft Word and Excel have been used to generate graphs, table etc.

\section{Results \& Discussion}

As we have a better understanding of drug pharmacology (dynamics and kinetics), the notion of modern day Total intravenous anaesthesia (IV) has popularized over a period of time from induction of general anaesthesia. In recent era it become routine due to the development of Intravenous (IV) drug infusion systems that are able to calculate and deliver accurately the infusion dose of a given Intravenous agent. Outpatient ambulatory surgery is the fastest growing segment of surgery and anaesthesia. ${ }^{[6,7]}$ Of all the intravenous anaesthetic agents that are available, Propofol's profiles 
favour for total intra venous anaesthesia. ${ }^{[9,10]}$ Pain relief to patient is an important constituent of balanced anaesthesia so inj Butorphanol iv and fentanyl iv medication was used as adjuvants in this study.

There were $19(47.5 \%)$ male and $21(52.5 \%)$ female in group I whereas $18(45 \%)$ male and $22(55 \%)$ female in group II. Both the groups were comparable with respect to sex, age, weight, height and ASA grading.

Group I received $20 \mu \mathrm{g} / \mathrm{kg}$ Inj. Butorphanol I.V. and Group II received $2 \mu \mathrm{g} / \mathrm{kg}$ Inj. Fentanyl I.V. according to patient selection. Gupta et al $(2011),{ }^{[19]}$ used $1 \mu \mathrm{g} / \mathrm{kg}$ Fentanyl and 20 $\mu \mathrm{g} / \mathrm{kg}$ Butorphanol (Similar to our study) but induction was done with Inj. Thiopentone $4 \mathrm{mg} / \mathrm{kg}$. Verma et al (2006), ${ }^{[20]}$ used Butorphanol $25 \mu \mathrm{g} / \mathrm{kg}$.

In both the groups induction was done with Inj. Propofol and Maintenance was started as a stepped down scheme by using infusion pump. Sukhminder Singh Bajwa et al (2010), ${ }^{[21]}$ used Propofol $1.5 \mathrm{mg} / \mathrm{kg}$ and Fentanyl $2 \mu \mathrm{g} / \mathrm{kg}$ for induction and for maintenance they used Propofol $2 \mathrm{mg} / \mathrm{kg} / \mathrm{hr}$ and Fentanyl $2 \mu \mathrm{g} / \mathrm{kg} / \mathrm{hr}$. Gupta et al $(2011),{ }^{[19]}$ have used inj propofol $2.5 \mathrm{mg} / \mathrm{kg}$ for induction and $0.5 \mathrm{mg} / \mathrm{kg}$ increment if required till loss of consciousness and eye lash reflex. Rao et al (2013), ${ }^{[22]}$ used Butorphanol $40 \mu \mathrm{g} / \mathrm{kg} \&$ Fentanyl $2 \mu \mathrm{g} / \mathrm{kg}$ and for induction thiopentone $5 \mathrm{mg} / \mathrm{kg}$. Regmi et al (2014), ${ }^{[23]}$ used Butorphanol $20 \mu \mathrm{g} / \mathrm{kg}$ and induction was done by $1.5 \mathrm{mg} / \mathrm{kg}$ Propofol. We used Butorphanol $20 \mu \mathrm{g} / \mathrm{kg} \mathrm{I.V}$. for the purpose of adequate surgical analgesia in superficial surgeries. The recommended maximum dose of Butorphanol is $40 \mu \mathrm{g} / \mathrm{kg}$ but many of the above studies showed $20 \mu \mathrm{g} / \mathrm{kg}$ Butorphanol is adequate. Higher doses of Butorphanol resulted in prolonged sedation and delayed discharge. Higher doses increase time to readiness and post-operative nausea and vomiting. Similarly, with Fentanyl, many studies had been conducted using $2 \mu \mathrm{g} / \mathrm{kg}$ Fentanyl as mentioned above.

Table 1: Showing comparison of type of surgeries in both the groups.

\begin{tabular}{|l|l|l|l|l|}
\hline Type of Surgery & \multicolumn{2}{|l|}{ Group I } & Group II \\
\hline & No. & \% & No. & \% \\
\hline Debridement & 11 & $27.5 \%$ & 12 & $30 \%$ \\
\hline Lipoma & 9 & $22.5 \%$ & 7 & $17.5 \%$ \\
\hline Fibro-adenoma Breast & 12 & $30 \%$ & 13 & $32.5 \%$ \\
\hline Incision \& Drainage & 8 & $20 \%$ & 8 & $20 \%$ \\
\hline Total & 40 & $100 \%$ & 40 & $100 \%$ \\
\hline
\end{tabular}

[Table 1] showing different types of surgeries patients undergone. It was comparable in both the groups. Average duration of surgery in each group was comparable $(\mathrm{P}$ value $=$ 0.9751). Regmi et al (2014) did study in patients undergoing elective short surgical procedure less than 60 minutes. ${ }^{[23]}$

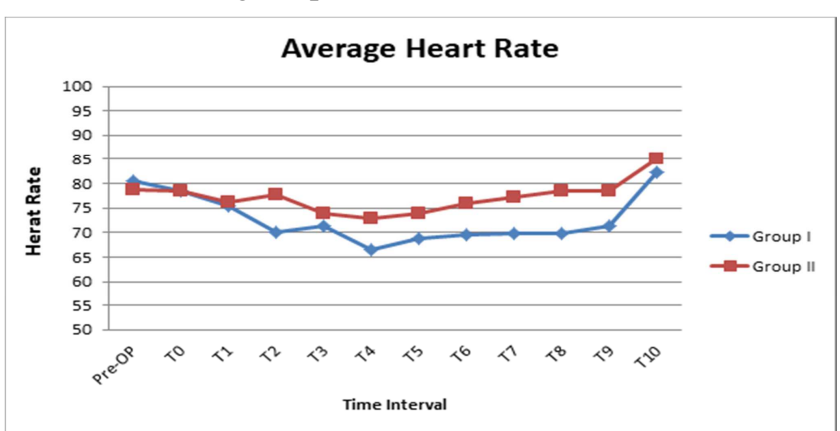

Figure 1: Line diagram showing average heart rate in both the groups.
Figure 1 shows changes in pulse rate during different time interval of study in either group. Pre-operative average pulse rate in either group was comparable. 1 min after giving Butorphanol/ Fentanyl, pulse rate decreased in both groups. The decrease was progressive in Butorphanol group. After giving Propofol, both the groups showed further decrease in pulse rate. At the time of incision, Butorphanol group showed further fall in pulse rate, while in Fentanyl group it remained almost same.

In Butorphanol group, throughout procedure, it remained low $\&$ at the end of surgery when Propofol infusion was stopped there was increase in average pulse rate.

While, in Fentanyl group pulse rate started to increase after $10 \mathrm{~min}$ of procedure till the end of procedure. However, pulse rate did not exceed beyond baseline (T0). This rules out inadequate analgesia. At the time of emergence when sedation score 3 , there was definite increase in pulse rate exceeding baseline in both the groups. At all levels, difference in pulse rate was not significant between the groups.

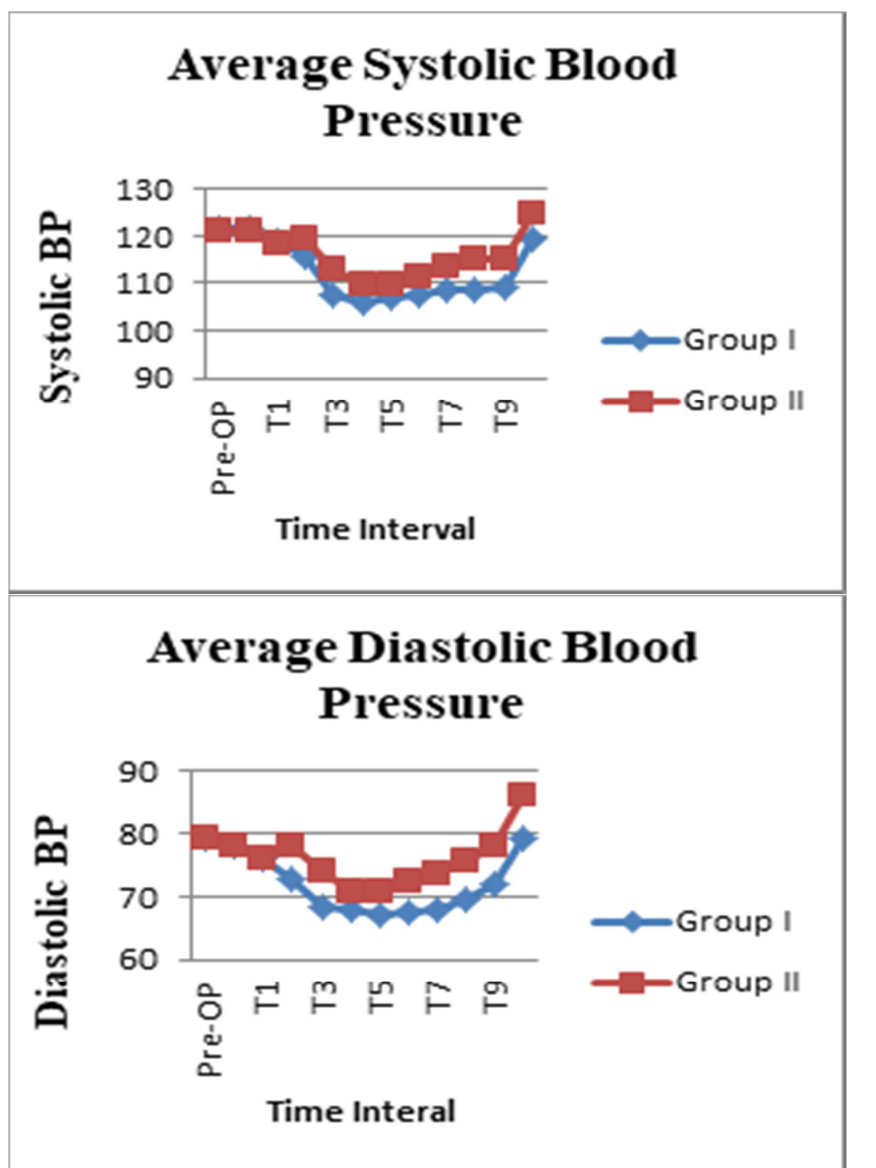

Figure $2 \&$ 3: Line diagram showing average Systolic and Diastolic blood pressure in both the groups.

In comparison with group I \& II, the SBP was comparable in both the groups, except at T3, here it was less in group I as compared to group II, but difference was significant after Propofol induction. In comparison to group I \& II, the DBP was comparable in both the groups except at T2, T3, T4 \& T5. There was significant fall in SDP and DBP in both groups compared to their pre-operative values after giving 
Butorphanol/Fentanyl and Propofol, which was seen till the end of surgery [Figure $2 \& 3$ ]. The comparison with group I \& II, the MBP was comparable in both the groups except at $\mathrm{T} 2$ \& T4. May be fall in MBP from basal level in Butorphanol group is more than Fentanyl group. There was significant fall in MBP in both groups compared to their preoperative values during the study. The decrease was in acceptable physiological limits.

In both the groups pre-operative respiratory rate was comparable. During study there was not any significant change in respiratory rate in both the groups. There was no any significant difference in $\mathrm{SpO} 2$ in both the groups throughout the study period. Arora et al $(2012),{ }^{[24]}$ also found comparable hemo-dynamics parameters at preoperative, induction \& maintenance level, after Butorphanol \& Fentanyl. But mean respiratory rate was lower in Butorphanol group as compared to Fentanyl group up to 3 post-operative hours, but no incidence of respiratory depression was seen in their study. Also, SpO2<92\% on room air was detected in $6 \%$ patients of Butorphanol group. May be due to higher dose of Butorphanol used i.e. $40 \mu \mathrm{g} / \mathrm{kg}$ in their study. Rao et al (2013), ${ }^{[73]}$ studied hemodynamic changes in relation to intubation \& found that, there was more decrease in pulse rate \& blood pressure in Butorphanol group as compared to Fentanyl group.

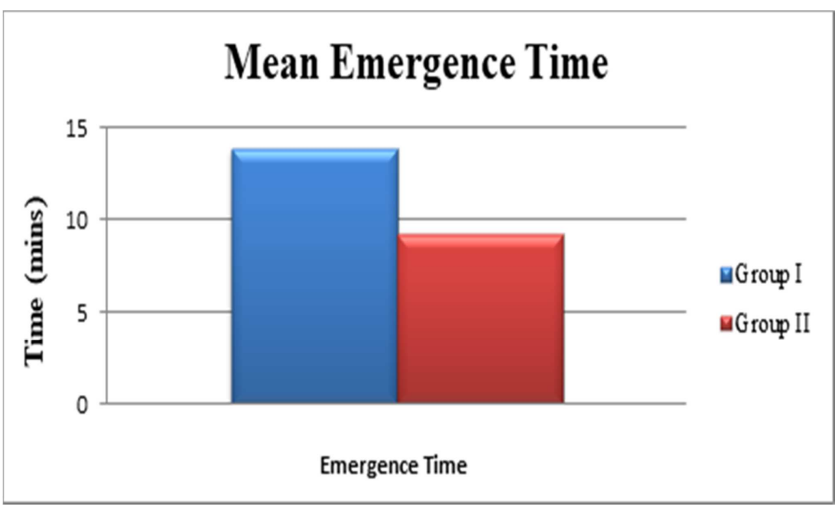

Figure 4: Bar Diagram of Mean Emergence Time in both the groups.

For mean emergence time unpaired $\mathrm{t}$ test was applied, $\mathrm{P}$ value $=0.04674$, So the difference was significant.

Emergence time was calculated from stoppage of Propofol infusion till patient showed Ramsay Sedation Score to be 3 . As shown in [Figure 4], emergence time was significantly prolonged in Butorphanol group as compared to Fentanyl group. Beverly K. et al (1991), ${ }^{[25]}$ found more sedation in Butorphanol group as compared to Fentanyl group. Verma et al $(2006),{ }^{[20]}$ also determined emergence time, but in his study, it was time period from stoppage of Propofol to extubation of trachea \& found that emergence time in Fentanyl group was significantly lesser than Butorphanol group. According to him, sedation to be the most common side effect associated with Butorphanol. We had not intubated patients but found that duration of sedation in Butorphanol group was significantly higher. Arora et al (2012), ${ }^{[24]}$ noted shorter recovery time in Fentanyl group but the difference was not statistically significant with Butorphanol group.

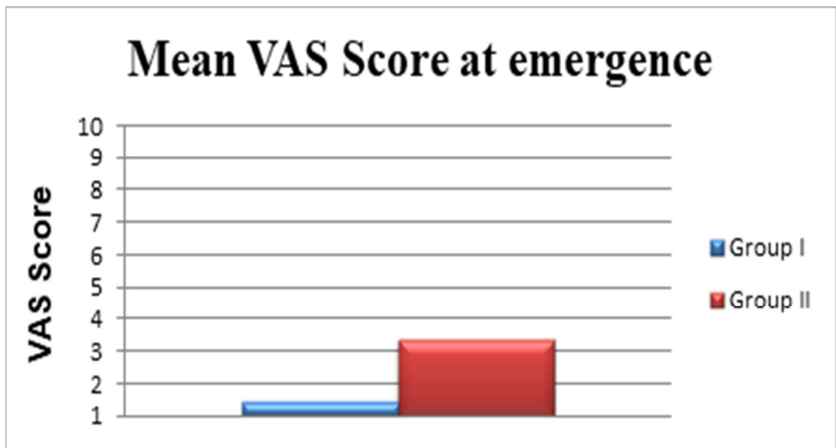

Figure 5: Bar Diagram of Mean VAS Score at the time of emergence in both the groups.

For mean Visual Analogue Score unpaired t test was applied. $\mathrm{P}$ value $=0.001$ So the difference was significant.

Visual Analogue Score (VAS) was recorded at the time of emergence to know the status of analgesia. Average VAS in Butorphanol patients was [1.425 \pm 0.6359$]$ less as compared to Fentanyl group $[3.375 \pm 0.8378]$ [Figure 5]. The difference was statistically significant, the patient receiving Fentanyl had definitely more pain as compared to Butorphanol group. Verma et al (2006), ${ }^{[20]}$ Rao et al (2013), ${ }^{[22]}$ found that post-operative analgesia was more in Butorphanol group as compared to Fentanyl group. We also observed the patients for adequate depth of anesthesia in the form of lacrimation, sweating, limb movement in addition to stable vitals i.e. HR, BP \& RR. We found for average $30 \mathrm{~min}$ of superficial surgery can be done in single pre-operative dose of Butorphanol or Fentanyl.

Butorphanol is a $\mathrm{K}$ receptor partial agonist and weak $\mu$ receptor antagonist. Whereas, Fentanyl pre dominantly $\mu$ receptor agonist. ${ }^{[25,26]}$ Therefore, Butorphanol is associated with more sedation than Fentanyl, as $\mathrm{K}$ agonist effect. ${ }^{[27]}$ Ability to produce analgesia is associated with both $\mathrm{\kappa}$ and $\mu$ receptors, with Butorphanol analgesia effect may be limited to partial $\mathrm{K}$ agonist activity. ${ }^{[28]}$

Receptor profile of Butorphanol also suggests that it should produce less respiratory depression than Fentanyl. Rapid redistribution of Fentanyl explains the early incidence of pain in Fentanyl patients. ${ }^{[24,29]}$ So, both the drugs showed reasonable results, but further studies will be needed with large numbers to conclude better correlation. Monitoring of depth of anaesthesia with BIS (Bis-pectoral Index) was one of the limitations of this study.

\section{Conclusion}

From the present study it can be concluded that, Butorphanol \& Fentanyl combined with Propofol in TIVA in short surgical procedures shows SBP, DBP \& MBP decreases in Butorphanol group more as compared to Fentanyl with little changes in HR between groups. Post-operative more time is taken for emergence in Butorphanol group. VAS score for pain at the time of emergence is more in Fentanyl group. So post-operative analgesia required for Fentanyl is early as compared to Butorphanol. With conventional observation, depth of anaesthesia is satisfactory in both the groups. So, both the drugs are adequate for short surgical procedures which are 30 or less in duration. 


\section{References}

1. Thiagarajan B.Total Intravenous Anaesthesia.Stanley medical college 2014.

2. Jarman, R., and Abel, A. L. (I936), "Pentothal Sodium, Intravenous Anaesthesia," Lancet, 1, 42.

3. M Morgan Total Intravenous Anaesthesia, Anaesthesia 1983;38: 1-9.

4. Robert FJ. Total intravenous anesthesia. Anaesthesiology 1996; 84:14951.

5. Kazuhiko Fukuda Opioids In R. D Miller editor Miller's Anesthesia 7th ed Churchill Livingstone Elsevier 802-3.

6. Wetcher PL: Anesthesia for ambulatory surgery 1990; 2nd Ed Philadelphia; Lippincott 640-55.

7. Hall MJ, Lawrence L: Ambulatory surgery in the United States, 1996. Adv Data 1998; 12: 1-16.

8. Manuel C Vallejo, Ryan C Romeo, Derek J Davis, SivamRamanathan: Propofol-ketamine versus propofol-fentanyl for outpatient laparoscopy, Comparison of postoperative nausea, emesis, analgesia and recovery. Journal of Clinical Anesthesia2002;14:426-31.

9. Kortilla K, Ostman P, Faure E, Apfelbaum JL, Prunstis I, Eddawi M, et al. Randomized comparison of recovery after propofol, nitrous oxide versus thiopentoneisoflurane-nitrous oxide anesthesia in patients undergoing ambulatory surgery. ActaAnesthesiolScand 1990; 34:40003.

10. Jakobson J, Davidson S, Andreen M, Westgreen M: Opioid supplementation to propofol anesthesia for outpatient abortion: A comparison between alfentanil, fentanyl and placebo. ActaAnesthesiolScand 1991;35:767-70.

11. Raeder JC, Stenseth LB. Ketamine: a new look at an old drug. CurrOpinAnaesthesiol 2000;13:463-68.

12. Stoelting RK, Hillier SC. Opioid Agonists and Antagonists. Pharmacology and Physiology in Anesthetic Practice. 4th ed. Philadelphia: Lippincott Williams and Wilkins; 2006;1:118-9.

13. Rosow CE. Butorphanol in perspective. Acute Care. 1988;12:2-7.

14. Auburn F, Salvi N, Coriat P, Riou B. Sex and age-related differences in morphine requirements for postoperative pain relief. Anaesthesiology. 2005;103:156-60.

15. C. maxwell. Sensitivity and accuracy of the Visual Analogous Score: A Psycho-Physical classroom experiment. Br. J. clin. Pharmac. 1978;6:1524.

16. Natalie Sigalovsky; Awareness under general anesthesia; AANA Journal; October 2003;71:5-15.

17. Prabhat Kumar Sinha, Thomas Koshy; Monitoring Devices for
Measuring the Depth of Anaesthesia - An Overview; Indian Journal of Anaesthesia 2007;51:365-81

18. Amornyotin Somchai; Monitoring for depth of anesthesia: a review; Journal of Biomedical Graphics and Computing, December 2012;2:215.

19. Gupta, Asha et al. "Comparative Evaluation of Ketamine - Propofol, Fentanyl - Propofol and Butorphanol-Propofol on Haemodynamics and Laryngeal Mask Airway Insertion Conditions." Journal of Anaesthesiology, Clinical Pharmacology 2011;27:74-78.

20. Verma R, S Jaiswal, P Rao, N Singh. Total Intravenous Anesthesia In Laparoscopic Cholecystectomy: Comparison Of Butorphanol And Fentanyl. The Internet Journal of Anesthesiology. 2006;14 :1:1-7.

21. SukhminderJit Singh Bajwa, SukhwinderKaur Bajwa1, JasbirKaur. Comparison of two drug combinations in total intravenous anesthesia: Propofol-ketamine and propofol-fentanyl Saudi J Anaesth.May august:2010;4:72-9.

22. Rao MH, Satyanarayana V, Srinivas B, Muralidhar A, AlokaSamantaray A, Krishna Reddy AS, Hemanth N. Comparison of butorphanol and fentanyl for balanced anaesthesia in patients undergoing laparoscopic surgeries under general anaesthesia: A prospective, randomized and double-blind study. J ClinSci Res 2013;2:8-15.

23. Regmi NK, Khatri S, Datta PK. Comparison of Propofol-Ketamine Combination with Propofol-Butorphanol Combination for Total Intravenous Anaesthesia on Short Surgical Procedures. JNGMC December.2014;12:34-9.

24. Arora V, Singh S, Bajwa, and Kaur S: Comparative evaluation of recovery characteristics of fentanyl and butorphanol when used as supplement to propofol anaesthesia. int J Appl Basic Med Res. 2012; 2(2):97-101.

25. Walter L. Way, Howard L. Fields, mark A.S. Opioid analgesics and antagonist. Basic and clinical Pharmo. 2001;8:512-30.

26. Howard B. Gutstein, Huda Akil Opioid analgesia. Goodman and Gilman 2001;10:569-611.

27. Beverly K., Scott, D.A., Freiberger, D. et al.Butorphanol compared with fentanyl in general anaesthesia for ambulatory laparoscopy Can J Anaesth.1991:38:183.

28. Heal R.C, Brodgen R.N, Speight T.M, Avery G.S. Butorphanol: A review of its pharmacological properties and therapeutic efficacy.Drugs: Feb 1979, 17: 2: 81-110.

29. Pandit, S.K., Kothary, S.P., Pandit, U.A. et al.: Comparison of fentanyl and butorphanol for outpatient anaesthesia Can J Anesth.1987;34:130.

Copyright: (c) the author(s), publisher. Academia Anesthesiologica International is an Official Publication of "Society for Health Care \& Research Development". It is an open-access article distributed under the terms of the Creative Commons Attribution Non-Commercial License, which permits unrestricted non-commercial use, distribution, and reproduction in any medium, provided the original work is properly cited.

How to cite this article: Trivedi A, Patel DC. Comparison of Propofol with Butorphanol and Propofol with Fentanyl for Total Intravenous Anaesthesia in Short Surgical Procedures. Acad. Anesthesiol. Int. 2019;4(2):263-7.

DOI: dx.doi.org/10.21276/aan.2019.4.2.59

Source of Support: Nil, Conflict of Interest: None declared. 